\title{
Neural correlates of spatial navigation changes in mild cognitive impairment and Alzheimer's disease
}

\author{
Kamil VIček ${ }^{1,2 *}$ and Jan Laczó ${ }^{2,3}$ \\ ' Department of Neurophysiology of Memory, Institute of Physiology, Academy of Sciences of the Czech Republic, Prague, Czech Republic \\ 2 International Clinical Research Center, St. Anne's University Hospital Brno, Brno, Czech Republic \\ ${ }^{3}$ Department of Neurology, 2nd Faculty of Medicine, Charles University in Prague and Motol University Hospital, Prague, Czech Republic
}

\section{Edited by:}

Tomiki Sumiyoshi, National Center of Neurology and Psychiatry, Japan

\section{Reviewed by:}

Eric Murillo-Rodriguez, Universidad

Anáhuac Mayab, Mexico

Eva Irle, University of Göttingen,

Germany

\section{${ }^{*}$ Correspondence:}

Kamil Vlček, Institute of Physiology, Academy of Sciences of the Czech

Republic, Vídenská 1083, Praha 4, 142

20 Prague, Czech Republic

e-mail: kamil@biomed.cas.cz
Although the memory impairment is a hallmark of Alzheimer's disease (AD), AD has also been characterized by spatial disorientation, which is present from its early stages. Spatial disorientation in AD manifests itself in getting lost in familiar and unfamiliar places and have been characterized more specifically using spatial navigation tests in both real space and virtual environments as an impairment in multiple spatial abilities, including allocentric and egocentric navigation strategies, visuo-spatial perception, or selection of relevant information for successful navigation. Patients suffering mild cognitive impairment $(\mathrm{MCl})$, who are at a high risk of development of dementia, show impairment in a subset of these abilities, mainly connected with allocentric and egocentric processing. While spatial disorientation in typical AD patients probably reflects neurodegenerative changes in medial and posterior temporal, parietal, and frontal lobes, and retrosplenial cortex, the impairment of spatial navigation in $\mathrm{MCl}$ seem to be connected mainly with the medial temporal and also parietal brain changes. In this review, we will summarize the signs of brain disease in most $\mathrm{MCl}$ and $A D$ patients showing in various tasks of spatial memory and navigation.

Keywords: Alzheimer's disease, mild cognitive impairment, spatial navigation, spatial disorientation, brain changes

\section{INTRODUCTION}

Spatial disorientation is one of the early manifestations of Alzheimer's disease $(\mathrm{AD})$, besides the clinically mostly used memory impairment. The research in spatial deficits in this neurodegenerative disease has grown rapidly in last years and decline in spatial navigation abilities may become another diagnostic mark for $\mathrm{AD}$ in the near future. Spatial navigation is however not a unitary function. This ability to determine and maintain a route from one place to another (Gallistel, 1990) utilizes multiple spatial strategies recruiting distinct brain regions.

This review aims to describe spatial disorientation in $\mathrm{AD}$ and mild cognitive impairment (MCI) as a multi-factorial deficit connected with changes in several brain regions. Various described manifestations of these changes in spatial cognitive tasks are the focus of this article. Selected for the review were only studies describing impairment in $\mathrm{AD}$ or MCI patients in real or virtual space, in spatial navigation, or associated abilities like perspective taking or object location memory.

\section{CURRENT VIEW ON SPATIAL DEFICITS IN AD AND MCI}

A number of studies focusing on visuo-spatial deficits in $\mathrm{AD}$ and $\mathrm{MCI}$ appeared during last two decades. The main published view on these deficits is broadly dual: one series of studies documented visuo-perceptual nature of the disorientation, its association with optic flow perception, and visuo-spatial attention (e.g., Tetewsky and Duffy, 1999; Cherrier et al., 2001; Mapstone et al., 2003; Kavcic et al., 2006). Another series of investigations stressed, however, the cognitive mapping deficits in these patients, specifically in using the allocentric navigation (Kalova et al., 2005; Hort et al., 2007;
Weniger et al., 2011; Nedelska et al., 2012). According to some other reports, the spatial disorientation in $\mathrm{AD}$ and MCI patients seem to be associated with both medial temporal and parietal lobe function (Henderson et al., 1989; deIpolyi et al., 2007). Several reviews on this theme published recently support either the latter allocentric view (Iachini et al., 2009) or combination of both cognitive mapping and visuo-perceptual factors (Vlcek, 2011; Gazova et al., 2012) or suggest a multifocal theory of disease developing from temporal to parietal and lateral to frontal brain and midbrain and associated cognitive deficits (Lithfous et al., 2013). One other review proposes the translation between egocentric and allocentric frames, supported by retrosplenial cortex (RSC), being the basis of spatial disorientation deficits in $\mathrm{MCI}$ and $\mathrm{AD}$ (Serino and Riva, 2013).

\section{BRAIN CHANGES IN MCI AND AD}

The anterior medial temporal lobe structures are the first affected by $\mathrm{AD}$ pathology. Histopathological changes initially occur in the entorhinal cortex and the hippocampus, further spread throughout parahippocampal gyrus to the temporal pole and inferior and middle temporal gyri in $\mathrm{MCI}$ and preclinical $\mathrm{AD}$, and subsequently spread throughout the temporal, parietal, and frontal neocortex by the time of dementia due to AD (Braak and Braak, 1995; Petersen et al., 2006). In agreement with this neuropathological staging, the highest rate of atrophy in the $\mathrm{MCI}$ and initial stages of AD has been found in the entorhinal and perirhinal cortices and the hippocampus (Pennanen et al., 2004; Schmidt-Wilcke et al., 2009; Risacher et al., 2010), which also showed accelerated volume loss over the time (Schuff et al., 2012) and hypometabolism (Karow et al., 2010). 
The anteromedial temporal atrophy was described even in cognitively normal individuals later converting to MCI (Smith et al., 2007). The posterior part of the gyrus, the parahippocampal cortex, is affected later in the course of AD (Karow et al., 2010; Spulber et al., 2012), followed by atrophy of the fusiform gyrus (McDonald et al., 2009).

A number of neuroimaging studies have also shown structural and metabolic changes in the parietal lobe, early in the course of AD. Cortical atrophy (Fennema-Notestine et al., 2009) in the precuneus and the inferior parietal lobule were reduced in the early MCI stages (McDonald et al., 2009) and volume reduction of these areas is the most consistent finding among the MCI to AD converters (Karas et al., 2008; Whitwell et al., 2008) and was described even in normal individuals later converting to MCI and AD (Smith et al., 2007; Jacobs et al., 2011). Hypometabolism was also found in superior parietal lobules (Li et al., 2008; Nobili et al., 2008) and even more in the inferior parietal lobule (Nobili et al., 2009) in MCI patients, especially those converting later to AD (Drzezga et al., 2003; Hirao et al., 2005).

Within the cingulate gyrus, the posterior cingulate and RSC are affected early in the course of AD. Atrophy of these areas was demonstrated in mild AD patients (Scahill et al., 2002) and patients with early stages of MCI (Chetelat et al., 2002; FennemaNotestine et al., 2009), especially in those later progressing to AD (Hamalainen et al., 2007; Whitwell et al., 2008; Julkunen et al., 2009; Pengas et al., 2010a). Severe posterior cingulate cortex hypometabolism is a feature of incipient $\mathrm{AD}$ (Nestor et al., 2003a,b) and is present already in the MCI patients (Huang et al., 2002; Ishiwata et al., 2006; Johnson et al., 2007; Pappata et al., 2010).

Neuropathological changes occur in the frontal cortex later in the course of AD (Braak and Braak, 1995; Petersen et al., 2006). Frontal lobe atrophy and hypometabolism is not present earlier than at the later stages of MCI and mainly in the prefrontal cortex (Fennema-Notestine et al., 2009; Langbaum et al., 2009; McDonald et al., 2009) but is more pronounced in those MCI patients who later converted to AD (Drzezga et al., 2003; Whitwell et al., 2008).

Although the described the brain changes prevails in $\mathrm{AD}$ and MCI patients, in a significant portion of AD patients the underlying neuropathological process follows alternative distribution, representing at least two other clinicopathological subtypes of $\mathrm{AD}$ and contrasting with the typical AD (Murray et al., 2011). In the hippocampal sparing AD subtype, found in $11 \%$ of patients, the neuronal degeneration results in lower gray matter volumes of lateral parietal, lateral temporal, and lateral frontal cortex, compared to typical AD (Whitwell et al., 2012). In the limbicpredominant AD subtype, found in $14-19 \%$ patients, the areas affected more than in the typical $\mathrm{AD}$ are the hippocampus and amygdala, with lower gray matter volumes. These differences are associated with distinct cognitive profiles in memory and other cognitive domains and necessarily also in spatial navigation, as well as with the different course of cognitive changes over time. However, the $\mathrm{AD}$ subtypes have not been considered in the studies reviewed below and the described deficits in spatial memory applies probably only to the predominating typical AD.

\section{SPATIAL NAVIGATION DEFICITS IN MCI AND AD ALLOCENTRIC NAVIGATION, OBJECT LOCATION MEMORY, AND SCENE PROCESSING}

Allocentric memory enables us to locate a goal in relation to surrounding objects and global landmarks, a function localized to medial temporal lobe, and hippocampus specifically (O'Keefe and Nadel, 1978; Maguire et al., 1998; Astur et al., 2002; Feigenbaum and Morris, 2004; Parslow et al., 2004). Hippocampal role in spatial deficits in $\mathrm{AD}$ and MCI have been documented by a series of allocentric navigation studies: $\mathrm{AD}$ patients were impaired in a real space analog of Morris water maze, termed blue velvet arena (BVA): only in allocentric trials when the cues on the wall could be used for orientation, but not in trials without cues, when only the start position could be used (Kalova et al., 2005). In the same apparatus, a more strictly defined AD group had problems navigating using both start position and cues on the walls, but an amnestic MCI single-domain group was impaired only in the allocentric trials (Hort et al., 2007), suggesting specific hippocampal impairment. This was supported later in a follow-up study where hippocampal amnestic MCI patients showed no learning in the allocentric trials (Laczo et al., 2009). Virtual analogy was also used in a recent study (Hort et al., 2014), where BVA was termed Urania. Amnestic MCI were also impaired in another allocentric navigation test to find shortest way to hidden targets in a virtual park (Weniger et al., 2011). A connection of allocentric navigation to hippocampal function was supported also in a study correlating real space Morris water maze analogy navigation successfulness with right hippocampal volume (Nedelska et al., 2012).

Successfulness in other spatial tasks is probably also connected to hippocampal function. Memory for temporal sequence of three body turns in a Starmaze was documented to activate left hippocampus (Igloi et al., 2010) and later shown to distinguish well between mild AD patients and controls (Bellassen et al., 2012). Memory for location of objects in space was several time consistently shown to be dependent on hippocampal function (Milner et al., 1997; Kessels et al., 2004; Stepankova et al., 2004) and reported to be deficient in patients suffering $\mathrm{AD}$ (Bucks and Willison, 1997; Brandt et al., 2005) and also in MCI patients, although to a lesser degree than in $\mathrm{AD}$ (Kessels et al., 2010). In contrast, memory for several positions without objects seem to be preserved even in mild AD (Adelstein et al., 1992; Kalova et al., 2005).

Processing of viewpoint independent spatial representation of a scene during scene matching seem also to be associated with hippocampal function after very short delays and with parahippocampal cortex function even in the presence of the sample scene (Hartley et al., 2007). In the same test, groups of six AD patients and seven amnestic MCI patients were impaired after short delays but not in direct scene matching (Bird et al., 2010), while a larger group of $\mathrm{AD}$ patients was impaired even in matching of simultaneously visible scenes (Pengas et al., 2010b). In a similar test, scene discrimination across different views was worsened in a selective hippocampal damage group (Lee et al., 2005) and also in a group of mild AD patients (Lee et al., 2006).

\section{REFERENCE FRAME TRANSLATION}

Retrosplenial cortex, a part of the posterior cingulate cortex, is strongly involved in spatial processing, specifically in translation 
between egocentric and allocentric representations (Byrne et al., 2007). Its damage shows as heading disorientation, an inability to derive directional information from scenes or to estimate spatial relationship between two locations (Aguirre and D'Esposito, 1999). Impairment of head orientation was also documented in AD but not MCI patients, reaching lower score in head orientation test, requiring to indicate directions after a test of navigation within a virtual city (Pengas et al., 2010b). Navigation score in this test correlated with gray matter density and glucose metabolism in RSC, but also hippocampus (Pengas et al., 2012). In another study on virtual as well as real navigation in a hospital lobby, AD patients, but again not MCI patients, were impaired in a test of self-orientation, requiring to indicate directions to scenes from the route (Cushman et al., 2008). The AD patients were also impaired in navigation in a virtual-reality maze using its map, which required translation of allocentric representation in the map to the egocentric direction in the maze (Morganti et al., 2013). Location of scenes on a map could possibly be also regarded as a behavioral measure of RSC function, requiring egocentric to allocentric translation. This ability was impaired in MCI patients in two studies focused on route learning and follow-up set of spatial tests (deIpolyi et al., 2007; Cushman et al., 2008).

\section{EGOCENTRIC NAVIGATION}

Egocentric memory enables us to remember positions in space in relation to one's own position and heading in space. The brain localization of the navigational strategy using egocentric reference frame seems to be diverse and possibly reflects multiplicity of strategies concealed under the usage of a single egocentric reference frame. The superior and inferior parietal lobe structures have been activated during various egocentric tasks in Morris water maze analogy (Parslow et al., 2004), virtual city (Maguire et al., 1998; Wolbers et al., 2004) as well as in landmark-free environment (Wolbers et al., 2008). The activity in caudated nucleus was associated with a response strategy in a virtual analogy of a radial maze (Iaria et al., 2003) and following a well-learned route in a virtual city (Hartley et al., 2003).

Egocentric navigation was documented to be impaired in $\mathrm{AD}$ and also MCI patients in two types of experiments. In a both real space and computer analogy of Morris water maze, amnestic MCI patients with associated non-memory impairment scored similarly to $\mathrm{AD}$ patients in finding of hidden goal position using only their starting position (Hort et al., 2007). In landmark-free virtual-reality maze, requiring the subjects to use only the sequence of egocentric turns during navigation, the amnestic MCI subjects were unable to learn a route to a hidden reward (Weniger et al., 2011). In addition, the number of errors in this maze correlated negatively with precuneus volume, supporting the assumption of egocentric strategy use.

\section{VISUAL PERCEPTION}

A wealth of reports document the role of visual perception functions in navigational impairment: either perception of optic flow, visuo-spatial attention, or visual perceptual analysis. The optic flow perception is supported by the visual area V5/MT at the junction of occipital, temporal, and parietal lobes (Morrone et al.,
2000). Connection of optic flow perception thresholds with navigation impairment in $\mathrm{AD}$ patients was described in studies using route learning in a hospital lobby (Tetewsky and Duffy, 1999) or indirectly using left-right orientation in table-top Money Road Map test (MRMT) and sustained driving in On-the-Road Driving test (O'Brien et al., 2001). Similar correlation between MRMT scores and optic flow perception was found also in MCI patients (Mapstone et al., 2003). Even better prediction of the navigation score in a hospital lobby was found in a combined regression model containing contrast sensitivity score and amplitude of the visual ERP N200 responses (Kavcic et al., 2006). This association of navigation score to visual perception could however be confined only to men patients (Cushman and Duffy, 2007), while in women patients the navigation score seem to be better predicted by verbal fluency and figural memory.

The perceptual nature of disorientation could be inferred also from other studies on $\mathrm{AD}$ patients. These patients were impaired in recognition of incidental landmarks not mentioned during the walk in a hospital lobby in contrast to correct recognition of the mentioned landmarks (Cherrier et al., 2001). In another study, also using route learning in a hospital lobby, the impairment of $\mathrm{AD}$ patients was predicted by MRMT and Line orientation test but not by mostly low memory scores (Monacelli et al., 2003). The impairment of $\mathrm{AD}$ patients in all angle categories of turns in MRMT, in combination with their normal left-right discrimination, have also been explained by visual perceptual deficits (Rainville et al., 2002). Similarly, visuoconstructive test scores together with results from a memory test predicted spatial disorientation sub-score from Memory and Behavior Problems Checklist questionnaire (Henderson et al., 1989), supporting the dual roots of $\mathrm{AD}$ disorientation.

\section{PLANNING AND PROBLEM SOLVING}

Deficits in frontal problem solving functions were documented in a unique experiment (Passini et al., 1995), requiring AD subjects to guide the experimenter to the dental clinic in an unknown hospital and to express verbally everything that went through their mind. To minimize the effect of memory and attentional deficit, the subjects were repeatedly reminded about their task. Their behavior was seemingly more driven by external stimuli than by the goal of the way-finding task, suggesting difficulties to distinguish relevant from irrelevant information and to structure their decision plan.

\section{LANDMARK RECOGNITION}

Individual recognition of landmarks, salient features of environment useful for navigation, is an isolated cognitive ability, impaired in landmark agnosia (Aguirre and D'Esposito, 1999) and dependent on the function of the anterior end of the right lingual gyrus (Aguirre et al., 1998; Mendez and Cherrier, 2003). Three real-world navigation studies report different successfulness in $\mathrm{AD}$ and MCI patients: in a series of tests after a walk in a hospital lobby, MCI and mild $\mathrm{AD}$ patients were similar to controls in landmarks recognition (deIpolyi et al., 2007), but were impaired in a more recent study (Benke et al., 2013). The relationship of this impairment to visuospatial attention are suggesting the results of an earlier study, where recognition of landmarks mentioned by experimenter during the walk was least impaired in $\mathrm{AD}$ patients, in contrast to their large 
impairment in recognition of landmarks not mentioned during the walk (Cherrier et al., 2001).

In contrast, in a free recall of landmarks along a route, the $\mathrm{AD}$ patients were found to be impaired (Monacelli et al., 2003) and this measure even distinguished reliably between MCI and healthy old subjects (Cushman et al., 2008).

\section{CONCLUSION}

Findings of this survey are mainly consistent with the described brain changes during spreading of the disease and suggest its propagation from the anterior medial temporal lobe to posterior temporal and parietal areas in MCI and to frontal and parieto-occipital areas later in $\mathrm{AD}$ patients. MCI patients seem to be impaired first in the allocentric navigation and later in the multi-domain stage also in egocentric navigation. Consistently with this double impairment, suggesting their medial temporal as well as posterior parietal damage, they have been found to be impaired also in route learning in both real and virtual environments. Short-term scene memory, visuo-spatial attention, and optic flow perception may also affect their navigational successfulness.

The broad cognitive impairment of even mild AD patients interferes also with other abilities essential for successful navigation, as optic flow perception, reference frame translation, scene matching, spatial planning, visual perceptual analyses, and possibly landmark recognition. Their navigation difficulties seem therefore to be connected with their more wide spread brain damage in other areas of parietal lobes and temporal cortex, RSC, as well as frontal lobes.

\section{AUTHOR CONTRIBUTIONS}

Both Kamil Vlček and Jan Laczó wrote and discussed the manuscript, contributed to the final version of the paper and have approved it.

\section{ACKNOWLEDGMENTS}

We would like to thank to Jakub Hort for his thorough revisions and comments. The study was supported by $\mathrm{MH}$ CR - IGA grant NT13386; ERDF - Project FNUSA-ICRC (No. CZ.1.05/1.1.00/02.0123); ESF and the State Budget of the CR; Young Talent Incubator II (Reg. no. CZ.1.07/2.3.00/20.0117); MH CR - DRO (University Hospital Motol, Prague, Czech Republic, 00064203); Institutional Support of Laboratory Research Grant No. 2/2012 (699002); research projects AV0Z 50110509 and RVO:67985823.

\section{REFERENCES}

Adelstein, T. B., Kesner, R. P., and Strassberg, D. S. (1992). Spatial recognition and spatial order memory in patients with dementia of the Alzheimer's type. Neuropsychologia 30, 59-67. doi:10.1016/0028-3932(92)90014-D

Aguirre, G. K., and D’Esposito, M. (1999). Topographical disorientation: a synthesis and taxonomy. Brain 122, 1613-1628. doi:10.1093/brain/122.9.1613

Aguirre, G. K., Zarahn, E., and D'Esposito, M. (1998). An area within human ventral cortex sensitive to "building" stimuli: evidence and implications. Neuron 21, 373-383. doi:10.1016/S0896-6273(00)80546-2

Astur, R. S., Taylor, L. B., Mamelak, A. N., Philpott, L., and Sutherland, R. J. (2002). Humans with hippocampus damage display severe spatial memory impairments in a virtual Morris water task. Behav. Brain Res. 132, 77-84. doi:10.1016/S0166-4328(01)00399-0

Bellassen, V., Igloi, K., de Souza, L. C., Dubois, B., and Rondi-Reig, L. (2012). Temporal order memory assessed during spatiotemporal navigation as a behavioral cognitive marker for differential Alzheimer's disease diagnosis. J. Neurosci. 32, 1942-1952. doi:10.1523/JNEUROSCI.4556-11.2012

Benke, T., Karner, E., Petermichl, S., Prantner, V., and Kemmler, G. (2013). Neuropsychological deficits associated with route learning in Alzheimer disease, MCI, and normal aging. Alzheimer Dis. Assoc. Disord. doi:10.1097/WAD. 0000000000000009

Bird, C. M., Chan, D., Hartley, T., Pijnenburg, Y. A., Rossor, M. N., and Burgess, N. (2010). Topographical short-term memory differentiates Alzheimer's disease from frontotemporal lobar degeneration. Hippocampus 20, 1154-1169. doi:10.1002/hipo.20715

Braak, H., and Braak, E. (1995). Staging of Alzheimer's disease-related neurofibrillary changes. Neurobiol. Aging 16, 271-278. doi:10.1016/0197-4580(95)00021-6 Brandt, J., Shpritz, B., Munro, C. A., Marsh, L., and Rosenblatt, A. (2005). Differential impairment of spatial location memory in Huntington's disease. J. Neurol. Neurosurg. Psychiatr. 76, 1516-1519. doi:10.1136/jnnp.2004.059253

Bucks, R. S., and Willison, J. R. (1997). Development and validation of the location learning test (LLT): a test of visuo-spatial learning designed for use with older adults and in dementia. Clin. Neuropsychol. 11, 273-286. doi:10.1080/ 13854049708400456

Byrne, P., Becker, S., and Burgess, N. (2007). Remembering the past and imagining the future: a neural model of spatial memory and imagery. Psychol. Rev. 114, 340-375. doi:10.1037/0033-295X.114.2.340

Cherrier, M. M., Mendez, M., and Perryman, K. (2001). Route learning performance in Alzheimer disease patients. Neuropsychiatry Neuropsychol. Behav. Neurol. 14, 159-168.

Chetelat, G., Desgranges, B., De La Sayette, V., Viader, F., Eustache, F., and Baron, J. C. (2002). Mapping gray matter loss with voxel-based morphometry in mild cognitive impairment. Neuroreport 13, 1939-1943. doi:10.1097/00001756200210280-00022

Cushman, L. A., and Duffy, C. J. (2007). The sex specificity of navigational strategies in Alzheimer disease. Alzheimer Dis. Assoc. Disord. 21, 122-129. doi:10.1097/WAD.0b013e318047df2f

Cushman, L. A., Stein, K., and Duffy, C. J. (2008). Detecting navigational deficits in cognitive aging and Alzheimer disease using virtual reality. Neurology 71, 888-895. doi:10.1212/01.wnl.0000326262.67613.fe

deIpolyi, A. R., Rankin, K. P., Mucke, L., Miller, B. L., and Gorno-Tempini, M. L. (2007). Spatial cognition and the human navigation network in AD and MCI. Neurology 69, 986-997. doi:10.1212/01.wnl.0000271376.19515.c6

Drzezga, A., Lautenschlager, N., Siebner, H., Riemenschneider, M., Willoch, F., Minoshima, S., et al. (2003). Cerebral metabolic changes accompanying conversion of mild cognitive impairment into Alzheimer's disease: a PET follow-up study. Eur. J. Nucl. Med. Mol. Imaging 30, 1104-1113. doi:10.1007/s00259-0031194- 1

Feigenbaum, J. D., and Morris, R. G. (2004). Allocentric versus egocentric spatial memory after unilateral temporal lobectomy in humans. Neuropsychology 18 , 462-472. doi:10.1037/0894-4105.18.3.462

Fennema-Notestine, C., Hagler, D. J. Jr, McEvoy, L. K., Fleisher, A. S., Wu, E. H., Karow, D. S., et al. (2009). Structural MRI biomarkers for preclinical and mild Alzheimer's disease. Hum. Brain Mapp. 30, 3238-3253. doi:10.1002/hbm. 20744

Gallistel, C. R. (1990). The Organization of Learning. Cambridge: The MIT Press.

Gazova, I., Vlcek, K., Laczo, J., Nedelska, Z., Hyncicova, E., Mokrisova, I., et al. (2012). Spatial navigation-a unique window into physiological and pathological aging. Front. Aging Neurosci. 4:16. doi:10.3389/fnagi.2012.00016

Hamalainen, A., Tervo, S., Grau-Olivares, M., Niskanen, E., Pennanen, C., Huuskonen, J., et al. (2007). Voxel-based morphometry to detect brain atrophy in progressive mild cognitive impairment. Neuroimage 37, 1122-1131. doi:10.1016/j. neuroimage.2007.06.016

Hartley, T., Bird, C. M., Chan, D., Cipolotti, L., Husain, M., Vargha-Khadem, F., et al. (2007). The hippocampus is required for short-term topographical memory in humans. Hippocampus 17, 34-48. doi:10.1002/hipo.20240

Hartley, T., Maguire, E. A., Spiers, H. J., and Burgess, N. (2003). The well-worn route and the path less traveled: distinct neural bases of route following and wayfinding in humans. Neuron 37, 877-888. doi:10.1016/S0896-6273(03)00095-3

Henderson, V. W., Mack, W., and Williams, B. W. (1989). Spatial disorientation in Alzheimer's disease. Arch. Neurol. 46, 391-394. doi:10.1001/archneur.1989. 00520400045018

Hirao, K., Ohnishi, T., Hirata, Y., Yamashita, F., Mori, T., Moriguchi, Y., et al. (2005). The prediction of rapid conversion to Alzheimer's disease in mild 
cognitive impairment using regional cerebral blood flow SPECT. Neuroimage 28, 1014-1021. doi:10.1016/j.neuroimage.2005.06.066

Hort, J., Andel, R., Mokrisova, I., Gazova, I., Amlerova, J., Valis, M., et al. (2014). Effect of donepezil in Alzheimer disease can be measured by a computerized human analog of the morris water maze. Neurodegener. Dis. 13, 192-196. doi:10.1159/000355517

Hort, J., Laczo, J., Vyhnalek, M., Bojar, M., Bures, J., and Vlcek, K. (2007). Spatial navigation deficit in amnestic mild cognitive impairment. Proc. Natl. Acad. Sci. U.S.A. 104, 4042-4047. doi:10.1073/pnas.0611314104

Huang, C., Wahlund, L. O., Svensson, L., Winblad, B., and Julin, P. (2002). Cingulate cortex hypoperfusion predicts Alzheimer's disease in mild cognitive impairment. BMC Neurol. 2:9. doi:10.1186/1471-2377-2-9

Iachini, T., Iavarone, A., Senese, V. P., Ruotolo, F., and Ruggiero, G. (2009). Visuospatial memory in healthy elderly, AD and MCI: a review. Curr. Aging Sci. 2, 43-59. doi:10.2174/1874612810902010043

Iaria, G., Petrides, M., Dagher, A., Pike, B., and Bohbot, V. D. (2003). Cognitive strategies dependent on the hippocampus and caudate nucleus in human navigation: variability and change with practice. J. Neurosci. 23, 5945-5952.

Igloi, K., Doeller, C. F., Berthoz, A., Rondi-Reig, L., and Burgess, N. (2010). Lateralized human hippocampal activity predicts navigation based on sequence or place memory. Proc. Natl. Acad. Sci. U.S.A. 107, 14466-14471. doi:10.1073/pnas. 1004243107

Ishiwata, A., Sakayori, O., Minoshima, S., Mizumura, S., Kitamura, S., and Katayama, Y. (2006). Preclinical evidence of Alzheimer changes in progressive mild cognitive impairment: a qualitative and quantitative SPECT study. Acta Neurol. Scand. 114, 91-96. doi:10.1111/j.1600-0404.2006.00661.x

Jacobs, H. I., Van Boxtel, M. P., Uylings, H. B., Gronenschild, E. H., Verhey, F. R., and Jolles, J. (2011). Atrophy of the parietal lobe in preclinical dementia. Brain Cogn. 75, 154-163. doi:10.1016/j.bandc.2010.11.003

Johnson, K. A., Moran, E. K., Becker, J. A., Blacker, D., Fischman, A. J., and Albert, M. S. (2007). Single photon emission computed tomography perfusion differences in mild cognitive impairment. J. Neurol. Neurosurg. Psychiatr. 78, 240-247. doi:10.1136/jnnp.2006.096800

Julkunen, V., Niskanen, E., Muehlboeck, S., Pihlajamaki, M., Kononen, M., Hallikainen, M., et al. (2009). Cortical thickness analysis to detect progressive mild cognitive impairment: a reference to Alzheimer's disease. Dement. Geriatr. Cogn. Disord. 28, 404-412. doi:10.1159/000256274

Kalova, E., Vlcek, K., Jarolimova, E., and Bures, J. (2005). Allothetic orientation and sequential ordering of places is impaired in early stages of Alzheimer's disease: corresponding results in real space tests and computer tests. Behav. Brain Res. 159, 175-186. doi:10.1016/j.bbr.2004.10.016

Karas, G., Sluimer, J., Goekoop, R., van der Flier, W., Rombouts, S. A., Vrenken, H., et al. (2008). Amnestic mild cognitive impairment: structural MR imaging findings predictive of conversion to Alzheimer disease. AJNR Am. J. Neuroradiol. 29, 944-949. doi:10.3174/ajnr.A0949

Karow, D. S., McEvoy, L. K., Fennema-Notestine, C., Hagler, D. J. Jr, Jennings, R. G., Brewer, J. B., et al. (2010). Relative capability of MR imaging and FDG PET to depict changes associated with prodromal and early Alzheimer disease. Radiology 256, 932-942. doi:10.1148/radiol.10091402

Kavcic, V., Fernandez, R., Logan, D., and Duffy, C. J. (2006). Neurophysiological and perceptual correlates of navigational impairment in Alzheimer's disease. Brain 129, 736-746. doi:10.1093/brain/awh727

Kessels, R. P., Hendriks, M., Schouten, J., Van Asselen, M., and Postma, A. (2004). Spatial memory deficits in patients after unilateral selective amygdalohippocampectomy. J. Int. Neuropsychol. Soc. 10, 907-912. doi:10.1017/S1355617704106140

Kessels, R. P., Rijken, S., Joosten-Weyn Banningh, L. W., Van SchuylenborghVAN Es, N., and Olde Rikkert, M. G. (2010). Categorical spatial memory in patients with mild cognitive impairment and Alzheimer dementia: positional versus object-location recall. J. Int. Neuropsychol. Soc. 16, 200-204. doi:10.1017/S1355617709990944

Laczo, J., Vlcek, K., Vyhnalek, M., Vajnerova, O., Ort, M., Holmerova, I., et al. (2009). Spatial navigation testing discriminates two types of amnestic mild cognitive impairment. Behav. Brain Res. 202, 252-259. doi:10.1016/j.bbr.2009.03.041

Langbaum, J. B., Chen, K., Lee, W., Reschke, C., Bandy, D., Fleisher, A. S., et al. (2009). Categorical and correlational analyses of baseline fluorodeoxyglucose positron emission tomography images from the Alzheimer's Disease Neuroimaging Initiative (ADNI). Neuroimage 45, 1107-1116. doi:10.1016/j.neuroimage.2008. 12.072
Lee, A. C., Buckley, M. J., Gaffan, D., Emery, T., Hodges, J. R., and Graham, K. S. (2006). Differentiating the roles of the hippocampus and perirhinal cortex in processes beyond long-term declarative memory: a double dissociation in dementia. J. Neurosci. 26, 5198-5203. doi:10.1523/JNEUROSCI.3157-05.2006

Lee, A. C., Buckley, M. J., Pegman, S. J., Spiers, H., Scahill, V. L., Gaffan, D., et al. (2005). Specialization in the medial temporal lobe for processing of objects and scenes. Hippocampus 15, 782-797. doi:10.1002/hipo.20101

Li, Y., Rinne, J. O., Mosconi, L., Pirraglia, E., Rusinek, H., DeSanti, S., et al. (2008). Regional analysis of FDG and PIB-PET images in normal aging, mild cognitive impairment, and Alzheimer's disease. Eur. J. Nucl. Med. Mol. Imaging 35, 2169-2181. doi:10.1007/s00259-008-0833-y

Lithfous, S., Dufour, A., and Despres, O. (2013). Spatial navigation in normal aging and the prodromal stage of Alzheimer's disease: insights from imaging and behavioral studies. Ageing Res. Rev. 12, 201-213. doi:10.1016/j.arr.2012.04.007

Maguire, E. A., Burgess, N., Donnett, J. G., Frackowiak, R. S., Frith, C. D., and O'Keefe, J. (1998). Knowing where and getting there: a human navigation network. Science 280, 921-924. doi:10.1126/science.280.5365.921

Mapstone, M., Steffenella, T. M., and Duffy, C. J. (2003). A visuospatial variant of mild cognitive impairment: getting lost between aging and AD. Neurology 60, 802-808. doi:10.1212/01.WNL.0000049471.76799.DE

McDonald, C. R., McEvoy, L. K., Gharapetian, L., Fennema-Notestine, C., Hagler, D. J. Jr, Holland, D., et al. (2009). Regional rates of neocortical atrophy from normal aging to early Alzheimer disease. Neurology 73, 457-465. doi:10.1212/ WNL.0b013e3181b16431

Mendez, M. F., and Cherrier, M. M. (2003). Agnosia for scenes in topographagnosia. Neuropsychologia 41, 1387-1395. doi:10.1016/S0028-3932(03)00041-1

Milner, B., Johnsrude, I., and Crane, J. (1997). Right medial temporal-lobe contribution to object-location memory. Philos. Trans. R. Soc. Lond. B Biol. Sci. 352, 1469-1474. doi:10.1098/rstb.1997.0133

Monacelli, A. M., Cushman, L. A., Kavcic, V., and Duffy, C. J. (2003). Spatial disorientation in Alzheimer's disease: the remembrance of things passed. Neurology 61, 1491-1497. doi:10.1212/WNL.61.11.1491

Morganti, F., Stefanini, S., and Riva, G. (2013). From allo- to egocentric spatial ability in early Alzheimer's disease: a study with virtual reality spatial tasks. Cogn Neurosci. 4, 171-180. doi:10.1080/17588928.2013.854762

Morrone, M. C., Tosetti, M., Montanaro, D., Fiorentini, A., Cioni, G., and Burr, D. C. (2000). A cortical area that responds specifically to optic flow, revealed by fMRI. Nat. Neurosci. 3, 1322-1328. doi:10.1038/81860

Murray, M. E., Graff-Radford, N. R., Ross, O. A., Petersen, R. C., Duara, R., and Dickson, D. W. (2011). Neuropathologically defined subtypes of Alzheimer's disease with distinct clinical characteristics: a retrospective study. Lancet Neurol. 10, 785-796. doi:10.1016/S1474-4422(11)70156-9

Nedelska, Z., Andel, R., Laczo, J., Vlcek, K., Horinek, D., Lisy, J., et al. (2012). Spatial navigation impairment is proportional to right hippocampal volume. Proc. Natl. Acad. Sci. U.S.A. 109, 2590-2594. doi:10.1073/pnas.1121588109

Nestor, P. J., Fryer, T. D., Ikeda, M., and Hodges, J. R. (2003a). Retrosplenial cortex (BA 29/30) hypometabolism in mild cognitive impairment (prodromal Alzheimer's disease). Eur. J. Neurosci. 18, 2663-2667. doi:10.1046/j.1460-9568. 2003.02999. $\mathrm{x}$

Nestor, P. J., Fryer, T. D., Smielewski, P., and Hodges, J. R. (2003b). Limbic hypometabolism in Alzheimer's disease and mild cognitive impairment. Ann. Neurol. 54, 343-351. doi:10.1002/ana.10669

Nobili, F., De Carli, F., Frisoni, G. B., Portet, F., Verhey, F., Rodriguez, G., et al. (2009). SPECT predictors of cognitive decline and Alzheimer's disease in mild cognitive impairment. J. Alzheimers Dis. 17, 761-772. doi:10.3233/JAD-2009-1091

Nobili, F., Frisoni, G. B., Portet, F., Verhey, F., Rodriguez, G., Caroli, A., et al. (2008). Brain SPECT in subtypes of mild cognitive impairment. Findings from the DESCRIPA multicenter study. J. Neurol. 255, 1344-1353. doi:10.1007/s00415008-0897-4

O’Brien, H. L., Tetewsky, S. J., Avery, L. M., Cushman, L. A., Makous, W., and Duffy, C. J. (2001). Visual mechanisms of spatial disorientation in Alzheimer's disease. Cereb. Cortex 11, 1083-1092. doi:10.1093/cercor/11.11.1083

O'Keefe, J., and Nadel, L. (1978). The Hippocampus as a Cognitive Map. Oxford: Clarendon Press.

Pappata, S., Varrone, A., Vicidomini, C., Milan, G., De Falco, C., Sansone, V., et al. (2010). SPECT imaging of GABA(A)/benzodiazepine receptors and cerebral perfusion in mild cognitive impairment. Eur. J. Nucl. Med. Mol. Imaging 37, 1156-1163. doi:10.1007/s00259-010-1409-1 
Parslow, D. M., Rose, D., Brooks, B., Fleminger, S., Gray, J. A., Giampietro, V., et al. (2004). Allocentric spatial memory activation of the hippocampal formation measured with fMRI. Neuropsychology 18, 450-461. doi:10.1037/0894-4105.18. 3.450

Passini, R., Rainville, C., Marchand, N., and Joanette, Y. (1995). Wayfinding in dementia of the Alzheimer type: planning abilities. J. Clin. Exp. Neuropsychol. 17, 820-832. doi:10.1080/01688639508402431

Pengas, G., Hodges, J. R., Watson, P., and Nestor, P. J. (2010a). Focal posterior cingulate atrophy in incipient Alzheimer's disease. Neurobiol. Aging 31, 25-33. doi:10.1016/j.neurobiolaging.2008.03.014

Pengas, G., Patterson, K., Arnold, R. J., Bird, C. M., Burgess, N., and Nestor, P. J. (2010b). Lost and found: bespoke memory testing for Alzheimer's disease and semantic dementia. J. Alzheimers Dis. 21, 1347-1365. doi:10.3233/JAD-2010100654

Pengas, G., Williams, G. B., Acosta-Cabronero, J., Ash, T. W., Hong, Y. T., IzquierdoGarcia, D., et al. (2012). The relationship of topographical memory performance to regional neurodegeneration in Alzheimer's disease. Front. Aging Neurosci. 4:17. doi:10.3389/fnagi.2012.00017

Pennanen, C., Kivipelto, M., Tuomainen, S., Hartikainen, P., Hanninen, T., Laakso, M. P., et al. (2004). Hippocampus and entorhinal cortex in mild cognitive impairment and early AD. Neurobiol. Aging 25, 303-310. doi:10.1016/S0197-4580(03) 00084-8

Petersen, R. C., Parisi, J. E., Dickson, D. W., Johnson, K. A., Knopman, D. S., Boeve, B. F., et al. (2006). Neuropathologic features of amnestic mild cognitive impairment. Arch. Neurol. 63, 665-672. doi:10.1001/archneur.63.5.665

Rainville, C., Marchand, N., and Passini, R. (2002). Performances of patients with a dementia of the Alzheimer type in the Standardized Road-Map test of Direction Sense. Neuropsychologia 40, 567-573. doi:10.1016/S0028-3932(01)00133-6

Risacher, S. L., Shen, L., West, J. D., Kim, S., McDonald, B. C., Beckett, L. A., et al. (2010). Longitudinal MRI atrophy biomarkers: relationship to conversion in the ADNI cohort. Neurobiol. Aging 31, 1401-1418. doi:10.1016/j.neurobiolaging. 2010.04.029

Scahill, R. I., Schott, J. M., Stevens, J. M., Rossor, M. N., and Fox, N. C. (2002). Mapping the evolution of regional atrophy in Alzheimer's disease: unbiased analysis of fluid-registered serial MRI. Proc. Natl. Acad. Sci. U.S.A. 99, 4703-4707. doi:10.1073/pnas.052587399

Schmidt-Wilcke, T., Poljansky, S., Hierlmeier, S., Hausner, J., and Ibach, B. (2009). Memory performance correlates with gray matter density in the ento-/perirhinal cortex and posterior hippocampus in patients with mild cognitive impairment and healthy controls - a voxel based morphometry study. Neuroimage 47, 1914-1920. doi:10.1016/j.neuroimage.2009.04.092

Schuff, N., Tosun, D., Insel, P. S., Chiang, G. C., Truran, D., Aisen, P. S., et al. (2012). Nonlinear time course of brain volume loss in cognitively normal and impaired elders. Neurobiol. Aging 33, 845-855. doi:10.1016/j.neurobiolaging.2010.07.012

Serino, S., and Riva, G. (2013). Getting lost in Alzheimer's disease: a break in the mental frame syncing. Med. Hypotheses 80, 416-421. doi:10.1016/j.mehy.2012.12.031

Smith, C. D., Chebrolu, H., Wekstein, D. R., Schmitt, F. A., Jicha, G. A., Cooper, G., et al. (2007). Brain structural alterations before mild cognitive impairment. Neurology 68, 1268-1273. doi:10.1212/01.wnl.0000259542.54830.34
Spulber, G., Niskanen, E., Macdonald, S., Kivipelto, M., Padilla, D. F., Julkunen, V., et al. (2012). Evolution of global and local grey matter atrophy on serial MRI scans during the progression from MCI to AD. Curr. Alzheimer Res. 9, 516-524. doi:10.2174/156720512800492486

Stepankova, K., Fenton, A. A., Pastalkova, E., Kalina, M., and Bohbot, V. D. (2004). Object-location memory impairment in patients with thermal lesions to the right or left hippocampus. Neuropsychologia 42, 1014-1028. doi:10.1016/ j.neuropsychologia.2004.01.002

Tetewsky, S. J., and Duffy, C. J. (1999). Visual loss and getting lost in Alzheimer's disease. Neurology 52, 958-965. doi:10.1212/WNL.52.5.958

Vlcek, K. (2011). "Spatial navigation impairment in healthy aging and Alzheimer's disease," in The Clinical Spectrum of Alzheimer's Disease - The Charge Toward Comprehensive Diagnostic and Therapeutic Strategies, ed. S. De La Monte (Rijeka, Croatia: InTech), 75-100.

Weniger, G., Ruhleder, M., Lange, C., Wolf, S., and Irle, E. (2011). Egocentric and allocentric memory as assessed by virtual reality in individuals with amnestic mild cognitive impairment. Neuropsychologia 49, 518-527. doi:10.1016/j. neuropsychologia.2010.12.031

Whitwell, J. L., Dickson, D. W., Murray, M. E., Weigand, S. D., Tosakulwong, N., Senjem, M. L., et al. (2012). Neuroimaging correlates of pathologically defined subtypes of Alzheimer's disease: a case-control study. Lancet Neurol. 11, 868-877. doi:10.1016/S1474-4422(12)70200-4

Whitwell, J. L., Shiung, M. M., Przybelski, S. A., Weigand, S. D., Knopman, D. S., Boeve, B. F., et al. (2008). MRI patterns of atrophy associated with progression to $\mathrm{AD}$ in amnestic mild cognitive impairment. Neurology 70, 512-520. doi:10.1212/01.wnl.0000280575.77437.a2

Wolbers, T., Hegarty, M., Buchel, C., and Loomis, J. M. (2008). Spatial updating: how the brain keeps track of changing object locations during observer motion. Nat. Neurosci. 11, 1223-1230. doi:10.1038/nn.2189

Wolbers, T., Weiller, C., and Buchel, C. (2004). Neural foundations of emerging route knowledge in complex spatial environments. Brain Res. Cogn. Brain Res. 21, 401-411. doi:10.1016/j.cogbrainres.2004.06.013

Conflict of Interest Statement: Dr. Jan Laczó has consulted for Pfizer and holds shares of Polyhymnia-TS. Authors declare that the research was conducted in the absence of any other commercial or financial relationships that could be construed as a potential conflict of interest.

Received: 17 January 2014; accepted: 01 March 2014; published online: 17 March 2014. Citation: Vlček K and Laczó J (2014) Neural correlates of spatial navigation changes in mild cognitive impairment and Alzheimer's disease. Front. Behav. Neurosci. 8:89. doi: 10.3389/fnbeh.2014.00089

This article was submitted to the journal Frontiers in Behavioral Neuroscience. Copyright (c) 2014 Vlček and Laczó. This is an open-access article distributed under the terms of the Creative Commons Attribution License (CC BY). The use, distribution or reproduction in other forums is permitted, provided the original author(s) or licensor are credited and that the original publication in this journal is cited, in accordance with accepted academic practice. No use, distribution or reproduction is permitted which does not comply with these terms. 